Aletria, Belo Horizonte, v. 30, n. 3, p. 179-200, 2020

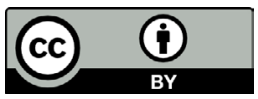

\title{
Contagem como o coração do mundo, através do olhar da produtora Filmes de Plástico
}

\author{
Contagem as the Heart of the World, Through \\ the Eyes of the Producer Filmes de Plástico
}

\author{
Geison de Almeida Bezerra da Silva \\ Pesquisador independente \\ jasaoalmeida@gmail.com \\ https://orcid.org/0000-0001-5624-0060
}

Resumo: O presente artigo visa abordar a trajetória da produtora audiovisual mineira Filmes de Plástico, sobretudo seu último longa-metragem, No coração do mundo (2019). Pretende-se também discutir as políticas de fomento ao audiovisual no Brasil, que, nas últimas duas décadas, foram responsáveis por inserir sujeitos e setores que foram excluídos do projeto de Estado-nação brasileiro e latino-americano. Parte-se do conceito, elaborado por Silviano Santiago (2004), de "cosmopolitismo do pobre", a fim de avaliar como as ideias propostas pelo articulista podem iluminar a discussão de projetos culturais no Brasil contemporâneo. Além dos conceitos de Santiago (2004), incorporam-se algumas ideias de Georges Didi-Huberman (2011) e Walter Benjamin (1987) que relacionam estética e política. Esse marco teórico contribui para pensar os elementos estéticos propostos pela produtora mineira, presentes em seu longa de 2019. Uma estética que valoriza a memória e o espaço onde estão as raízes culturais daqueles à frente da produtora.

Palavras-chaves: cinema; ANCINE; política; cultura; estética; No coração do mundo; Filmes de Plástico.

Abstract: This article aims to address the trajectory of the Minas Gerais-based audiovisual production company Filmes de Plástico, focusing on the company's latest feature film No coração do mundo (2019). We also intend to discuss the audiovisual promotion policies in Brazil which, for the past two decades, were responsible for 
inserting subjects and sectors that were excluded from the Brazilian and Latin American nation-state project. We start with the concept of "cosmopolitanism of the poor", coined by Silviano Santiago (2004). The paper explores to what extent the ideas proposed by the writer are useful for enlightening the discussion about cultural projects in contemporary Brazil. In addition to the concepts developed by Santiago (2004), it incorporates some ideas by Georges Didi-Huberman (2011) and Walter Benjamin (1987) that relate aesthetics to politics. These discussions are also helpful when thinking about the aesthetic elements proposed by Filmes de Plástico in their production, which can be spotted in their 2019 feature film. The film's aesthetic foregrounds the cultural roots of those at the forefront of the production, valuing the memory and the space which compose those roots.

Keywords: cinema; ANCINE; politics; culture; aesthetics; No coração do mundo; Filmes de Plástico.

O final da segunda década do século XXI, para a produção cinematográfica brasileira, pode ser visto por dois planos. O primeiro remete a um recente passado, a partir da criação, em 2001, da Agência Nacional de Cinema (ANCINE), por meio da medida provisória 2228-1 (ANCINE, [200-?]); já o segundo, se direciona ao presente de incertezas quanto a um futuro de liberdade de expressão, em virtude de uma postura intervencionista do Estado brasileiro ao sugerir possíveis "filtros" para a seleção de projetos cinematográficos. Se, por um lado, o presente do cinema nacional passa por uma crise institucional, os anos anteriores indicavam avanços tanto para a expansão quanto para a disseminação da cultura audiovisual no país e no exterior. As políticas de fomento ao cinema e ao audiovisual brasileiros, com aportes estaduais e federais, foram responsáveis pelo crescimento dos números de produções, de público, e de salas exibidoras (cf. ANCINE, 2017). Por meio delas, alguns grupos e sujeitos, muitas vezes marginalizados, inseriram-se no universo estético do cinema.

Um resultado efetivo desse estímulo é a produtora mineira Filmes de Plástico, formada, em 2009 pelos diretores André Novais Oliveira, Gabriel Martins e Maurílio Martins, além do produtor Thiago Macêdo Correia. Completando agora onze anos de existência, esse coletivo já

\footnotetext{
${ }^{1}$ Este termo foi utilizado por Jair Bolsonaro, Presidente da República em exercício, no ano de 2019 (cf. MAZUI, 2019).
} 
possui um repertório que contempla mais de uma dezena de curtasmetragens, bem como três longas, dos quais se destacam: Temporada (2018) e No coração do mundo (2019). Ainda que nem toda produção tenha sido financiada por leis de incentivo, é inegável que alguns editais foram importantes para consolidar alguns projetos e, com isso, ajudar na projeção das obras, que já estava em curso, em festivais e em premiações internacionais. O prestígio adquirido ao longo de mais de uma década rendeu à produtora, em 2019, uma homenagem feita pela $13^{\mathrm{a}}$ CineBH - Mostra Internacional de Cinema de Belo Horizonte (cf. PRODUTORA..., 2019).

Acompanhar a trajetória dessa pequena produtora de Minas Gerais, com ênfase no seu longa de 2019, é uma via crítica que lança luzes sobre o recente passado de possibilidades otimistas para a produção audiovisual e cultural no Brasil. Percorrer a vereda trilhada por esses jovens produtores significa dar visibilidade aos produtos culturais periféricos que estavam em vias de ganhar corpo e voz nos últimos anos, bem como ser uma alternativa de enfrentamento e resistência a um projeto de desmantelamento de políticas culturais brasileiras, as quais se fortaleciam nos dois últimos decênios e abriam algumas perspectivas para que agentes culturais que ainda ocupam a marginalidade de planos sociais e culturais da nação, pudessem atuar de forma mais efetiva. Por grupos e setores marginais entendem-se: os povos nativos brasileiros, os negros, as mulheres, as minorias sexuais e de gênero, os habitantes de periferias e conglomerados urbanos, entre outros.

A percepção de que a virada do século XX para o XXI trazia consigo um horizonte positivo de visibilidade a tais setores que foram excluídos de projetos nacionais - estes últimos relacionados às noções de modernização e de identidade cultural do país -, está presente no pensamento de vários intelectuais. No entanto, deve ficar claro que tal visão, embora possuísse uma face de esperança, não era ingênua e reduzida no que diz respeito à possibilidade de redenção histórica desses sujeitos no corpo da sociedade. Pensava-se que o desenvolvimento e as novas demandas de mercado seriam as responsáveis por aderir tais grupos em seu projeto, porém uma adesão ainda controlada e determinada pelos ritmos e ditames desse mesmo mercado. Entre os escritores, teóricos e críticos que vislumbraram esse cenário alternativo, aberto e em expansão, pode-se citar Silviano Santiago. Esse crítico, logo nos primeiros anos do nascente século, indicava que havia uma reorganização em curso de muitos 
Estados-nações, orientada a fortalecer a luta política de migrantes nas megalópoles, bem como daqueles que o projeto de modernização excluiu. Em 2002, o crítico trabalhou com a noção que ele mesmo nomeou como "cosmopolitismo do pobre", em um artigo que tinha como título justamente essa ideia cunhada por ele. Para lidar com esse conceito, o autor primeiramente recorreu à análise de uma produção cinematográfica luso-francesa de 1997, Viagem ao começo do mundo, ${ }^{2}$ realizada por Manoel de Oliveira. Segundo o articulista, existem ali dois filmes, ou dois pontos de vistas, em paralelo: o relato do personagem que figurava um diretor de cinema e outro, sobre a busca de um famoso ator por suas raízes lusitanas (SANTIAGO, 2004). A partir dessa dupla leitura do filme, o teórico propôs uma série de questionamentos a respeito de variados conceitos caros aos estudos de crítica cultural, como colonialismo, hibridização, aculturação, entre outros. Ao abordar a postura do velho diretor, Santiago (2004, p. 47, grifo do autor) executa um paralelo entre aquele personagem e a maioria dos artistas e intelectuais do século $\mathrm{XX}$, os quais, segundo ele, "passaram pela experiência da madeleine" (SANTIAGO, 2004, p. 47, grifo do autor). Ao trazer a mítica cena de Proust, o teórico se coloca em um intenso debate a respeito de uma postura muitas vezes colonialista de determinados grupos de intelectuais, cujas experiências de memória recaem inevitavelmente sobre um passado glorioso, aristocrático e senhorial, assim como faz o personagem de diretor de filmes em Viagem ao começo do mundo (SANTIAGO, 2004).

A segunda história, a do personagem ator, também é desenvolvida pelo articulista com a pena da crítica cultural. Essa, por sua vez, diz respeito à perda do idioma português, a qual afastou o ator de seus antepassados pelo processo de hibridização, seguido de aculturação de suas raízes. A viagem empreendida pelo ator é inversa à de seu pai, que saiu pobre da periferia europeia (Portugal) para chegar ao centro (França) ${ }^{3}$ como um clandestino trabalhador. O personagem sai do centro cosmopolita, com a distinção de ser um reconhecido ator internacional, para se dar conta de uma irreparável perda que o fluxo de capitais disponível nas megalópoles

\footnotetext{
${ }^{2}$ Há várias traduções que nomeiam esse filme como Viagem ao princípio do mundo, no entanto optou-se por citar a forma como o articulista Silviano Santiago propôs em seu artigo (SANTIAGO, 2004).

${ }^{3}$ Nomear Portugal e França como periferia e centro, respectivamente, faz parte da organização argumentativa proposta por Silviano Santiago (2004).
} 
não é capaz de suprir a perda do idioma, ou seja, da linguagem que seria um elo entre o seu presente e o seu passado.

Após fazer o paralelo entre o filme de 1997 e alguns conceitos relacionados à crítica cultural, Santiago (2004) abriu sua argumentação para uma distinção, proposta por ele, entre o antigo e o atual multiculturalismo. Em relação ao antigo, Santiago (2004) situava que os países, em especial os latino-americanos, recém-independentes do jugo colonizador europeu, tiveram que organizar suas identidades, instituindo, sobretudo no Brasil, a ideia de síntese étnico-racial, a qual adquire grande força a partir do trabalho de autores como Gilberto Freyre. Para Santiago (2004, p. 55-56), tal síntese teve como "dominantes, no caso brasileiro, [...] o extermínio dos índios, o modelo escravocrata de colonização, o silêncio das mulheres e das minorias sexuais". Tratando mais claramente da manutenção escravagista no país, Roberto Schwarz (2000) concebeu como "ideias fora de lugar" as concepções a respeito não somente do modelo multicultural de Estado-nacional aludido por Silviano Santiago, no Brasil, mas principalmente as bases de pensamento que fundamentavam este projeto.

A relação entre as noções de Estado-nação, identidades culturais e modernização propostas por Silviano Santiago são explicitadas por vários teóricos. Os dois excertos a seguir, presentes na obra de Stuart Hall (2011), são bastante elucidativos dessa questão, ainda que o ponto de vista deste autor esteja mais direcionado à América anglo-saxônica e à Europa. Para Hall (2011, p. 50),

[a] formação de uma cultura nacional contribuiu para criar padrões de alfabetização universais, generalizou uma única língua vernacular como o meio dominante de comunicação em toda a nação, criou uma cultura homogênea e manteve instituições culturais nacionais, como, por exemplo, um sistema educacional nacional. Dessa e de outras formas, a cultura nacional se tornou uma característica-chave da industrialização e um dispositivo da modernidade. (HALL, 2011, p. 50)

[...] Segundo o autor, "não importa quão diferentes seus membros possam ser em termos de classe, gênero ou raça, uma cultura nacional busca unificá-los numa identidade cultural, para representá-los todos como pertencendo à mesma e grande família nacional" (HALL, 2011, p. 60). 
Já aquilo que Santiago (2004) nomeou como o "atual multiculturalismo" é o ponto de chegada à argumentação proposta por esse articulista. Para ele, o multiculturalismo, que se projetava na virada do século XX para o XXI, propunha-se como uma alternativa, sem ser, contudo, uma superação às mazelas que o antigo modelo provocou. Mazelas que se referem à anulação ou à desarticulação de identidades diversas, a fim de estabelecer um projeto universalista de escamotear diferenças. Entendido dessa maneira, Santiago (2004, p. 59-60) apontava que "a cultura nacional estaria (ou deve estar) ganhando uma nova reconfiguração que, por sua vez, levaria (ou está levando) os atores culturais pobres a se manifestarem por uma atitude cosmopolita". A título de exemplificação dessa reconfiguração dos sujeitos marginalizados e dos países periféricos, o autor apresentou duas ações do movimento afrobrasileiro que visavam se reconectar e atribuir uma valorização cultural aos seus antepassados africanos. Desse modo, o autor apontava para as possibilidades enunciativas dessas identidades que foram negligenciadas durante o processo de construção cultural da sociedade brasileira, mas que, naquele momento, estavam atuando e, principalmente, ocupando espaços que antes lhes pareciam inacessíveis. Para concluir sua discussão, naquele estudo, o autor enalteceu a experiência e a troca realizadas entre o grupo de teatro marginalizado Nós do Morro e outros agentes culturais. Tal encontro teve como resultado a valorização de muitas pessoas oriundas da favela do Vidigal, que compuseram o elenco do premiado filme Cidade de Deus (2002), dirigido por Fernando Meireles e codirigido por Kátia Lund.

As colocações de Silviano Santiago (2004), em perspectiva com a conjuntura política brasileira do início da segunda década do século XXI, podem parecer desgastadas e ultrapassadas, visto que os discursos de alguns secretários e dirigentes culturais que se alçaram ao poder nas eleições de 2018, no Brasil, estão em franca oposição à alternativa multicultural que o crítico delineou em 2004. No entanto, esse veredicto melancólico é dado a partir de uma análise que se restringe a uma visão localizada, circunstancial e, na maioria das vezes, superficial. Localizada e circunstancial, pois direciona o ponto de vista apenas para o presente contexto brasileiro extremamente polarizado, que muitas vezes determina as formas de olhar para os objetos artísticos produzidos no país e fora dele, em especial, em países latino-americanos. 
Tomando apenas o cinema como exemplo, essa visão localizada e circunstancial pode ser questionada, uma vez que vários produtores(as), diretores(as), roteiristas, atores e atrizes se destacam, com trabalhos de grande expressão. No Brasil, tratando apenas de dois nomes que se fizeram mais notórios recentemente, é possível citar as mais recentes produções de Kleber Mendonça Filho, Aquarius (2016) e Bacurau (2019), ambos indicados e premiados em grandes festivais e premiações nacionais e internacionais. Além de Kleber Mendonça Filho, é importante mencionar a indicação do documentário da mineira Petra Costa, Democracia em vertigem (2019), à principal premiação do cinema mundial, o Oscar. Já em outros países latino-americanos, tomando apenas as produções que ganharam maior visibilidade, devido à conquista do Oscar, vale lembrar os mais recentes filmes vencedores da categoria Melhor Filme Estrangeiro: o chileno Uma mulher fantástica (2017), direção de Sebastián Lelio, e o mexicano Roma (2018), dirigido por Alfonso Cuarón. Esses exemplos de destaque da produção de cinema latino-americano são claramente paradigmáticos em relação à noção cosmopolita apregoada por Santiago (2004), na medida em que a maioria desses filmes dá ênfase a discussões caras aos sujeitos pobres, excluídos e marginalizados das sociedades contemporâneas. Enredos que atingem, ou que tocam, o mainstream da produção cinematográfica internacional, a partir de temas e questões sensíveis e urgentes para vários setores sociais, como a visibilidade transexual, a questão do imigrante, bem como do habitante de regiões extremamente carentes. Além de dar visibilidade a crises institucionais e políticas nesses países, e em especial no Brasil, e também discutir os modos como mercados e especulação imobiliária atingem diretamente vários grupos e sujeitos.

Uma análise que porventura pressuponha o desgaste crítico das ideias propostas por Silviano Santiago (2004) a respeito do "cosmopolitismo do pobre", também possui uma visão muito superficial da produção audiovisual brasileira e latino-americana. Tal visão se relaciona justamente a essa anterior exemplificação, na medida em que os exemplos apresentados são baseados apenas na filmografia que ganhou maior visibilidade no cenário internacional. Um olhar direcionado a um mundo, tomando de empréstimo os pensamentos de Georges DidiHuberman em Sobrevivência dos vaga-lumes, p. 155, 
inundado de luz, [onde] nos querem fazer acreditar, agitam-se aqueles que chamamos hoje - por uma cruel e hollywoodiana antifrase - alguns poucos people, ou seja, as stars - as estrelas, que, como se sabe, levam os nomes de divindades - sobre as quais regurgitamos informações na maior parte inúteis. (DIDI-HUBERMAN, 2011, p. 155).

Esse pensamento de Didi-Huberman (2011) estabelece uma distinção entre a grande luz e a pequena, produzida por lampejos, sendo que esta última o crítico associa à ideia de vaga-lumes. A primeira é entendida como o mainstream, coberto por tapetes vermelhos, flashes, projetores e canhões de luzes. Já a segunda seriam as margens, "território infinitamente mais extenso, [onde] caminham inúmeros povos sobre os quais sabemos muito pouco" (DIDI-HUBERMAN, 2011, p. 155). As discussões propostas por Didi-Huberman no estudo a respeito dos "vagalumes" relacionam a vida e a obra do cineasta Pier Paolo Pasolini, bem como os deslocamentos e posições políticas do artista. A obra de Pasolini, segundo o filósofo, transitou por esses dois espaços, (grandes luzes e lampejos) e, por meio desse trânsito, abriu possibilidades alternativas para se pensar a potência de imagens que estão fora da grande luminosidade do mercado cinematográfico.

O segundo território descrito pelo crítico francês, de luzes intermitentes vindas das margens, é mais amplo. Nele encontram-se várias ramificações e profundidades, as quais contribuem para o entendimento a respeito da produção audiovisual brasileira e, por extensão, latinoamericana. As veredas, seguidas por esses lampejos, indicam alguns rumos não tão visíveis que as políticas públicas culturais puderam, a ainda podem, alcançar. Políticas - potencializadas por agências reguladoras como a ANCINE, em plano nacional, e por outros projetos de incentivo de âmbito estadual - propiciaram, ao longo de quase duas décadas, um trabalho que ultrapassou a questão da audiência e da hipervisibilidade. Ainda que muito daquilo que é produzido por meio de financiamento público no audiovisual brasileiro não ocupe as grandes salas de cinemas (as grandes luzes) - hoje localizadas em sua maioria em shopping centers -, tais políticas tiveram o intuito de permitir trabalhos de formação de produtores, bem como de fomentar pequenas produções, muitas vezes oriundas de sujeitos e de setores marginalizados. É válido ressaltar que a questão de distribuir essa produção periférica a um público mais amplo seria mais um ponto a se discutir, a fim de que tais políticas cumpram 
seus outros objetivos, porém tal discussão não está nas dimensões e objetivos deste texto.

É a partir de um dos eixos normativos das políticas públicas, qual seja, fomentar a cultura audiovisual em vários grupos e setores sociais, que aquelas projeções de Silviano Santiago (2004) ganham força. Ideias e noções que carecem de ser recuperadas, principalmente para o debate cultural no atual contexto brasileiro. Tal necessidade fica patente a partir de um olhar histórico que visa analisar as duas últimas décadas, em que de fato houve, mesmo que precisassem ser mais bem disseminados, projetos políticos de fortalecimento e de resgate de "grupos étnicos e sociais, economicamente desfavorecidos no processo assinalado de multiculturalismo a serviço do estado-nação" (SANTIAGO, 2004, p. 59). Fazer esse percurso é, de certa forma, olhar para as pessoas que produzem arte no Brasil, apesar das dificuldades de acessar os espaços mais consagrados. Em outras palavras, é "nos tornar vaga-lumes e, dessa forma, formar novamente uma comunidade do desejo, uma comunidade de lampejos emitidos, de danças apesar de tudo, de pensamentos a transmitir. Dizer sim na noite atravessada de lampejos e não se contentar em descrever o não da luz que nos ofusca" (DIDI-HUBERMAN, 2011, p.154-155). Nesse sentido, é necessário olhar para a atualidade que se projeta como uma possível ameaça e buscar resistir a ela, de forma a reorientar um projeto que, ainda com carências, abria possibilidades para que setores marginalizados pudessem produzir.

A trajetória da produtora mineira Filmes de Plástico figura-se como um dos possíveis exemplares para a perspectiva de enfrentamento dessa ameaça, bem como de fortalecimento de grupos sociais, enunciados por Santiago (2004), na medida em que a origem dos idealizadores desse pequeno empreendimento audiovisual remete a um bairro localizado na periferia tanto da cidade de Contagem quanto da capital Belo Horizonte, ambas em Minas Gerais. Ao fortalecer esse pequeno grupo, as políticas públicas culturais abriram perspectivas tanto de trabalho quanto também de ampliação do horizonte, não somente dos pequenos produtores, mas principalmente de toda a comunidade da qual os jovens realizadores fazem parte. Assim, ao habitante dessa localidade, tornou-se possível se imaginar e se reconhecer em telas de cinema ou mesmo em vídeos disseminados pela internet, por meio de plataformas de streaming, além de alguns canais de TV por assinatura e abertos. 
Em uma entrevista dada ao portal O Tempo, os diretores e realizadores Gabriel e Maurílio Martins brincam com o estranhamento inicial por que tiveram que passar quando buscavam fazer imagens e cenas em seus respectivos bairros (cf. NO CORAÇÃO..., 2019). Um estranhamento comum a pessoas muitas vezes alheias a processos de produção cultural, ao dizer principalmente do cinema, que exige não somente os tecnológicos equipamentos, mas também os artifícios técnicos de sequência, enquadramento, atuação, iluminação, continuidade, corte, entre outros. Esse estranhamento, porém, segundo os cineastas, está cada vez mais diluído, devido à recorrência de filmagens que eles levam para essas localidades. Eles não somente disseminam e fortalecem a arte audiovisual nesses espaços como também a naturalizam, retirando a arte cinematográfica de uma possível aura, em termos benjaminianos, a qual muitas vezes impede a aproximação de algumas pessoas.

Foi nas aulas e nos corredores da Escola de Cinema do Centro Universitário UNA - uma instituição privada, situada em uma região nobre de Belo Horizonte - que ocorreu o primeiro encontro entre os dois realizadores, moradores de bairros vizinhos, Jardim Laguna e Milanez, da cidade de Contagem. Os trabalhos de conclusão de curso de ambos os cineastas fazem hoje parte do repertório da produtora. Trabalhos que, por sua vez, contaram com recursos exíguos para a sua execução. Essas últimas informações servem como um parêntesis oportuno para pontuar aspectos que se referem às Universidades como locais de encontro de pessoas criativas e ativas no cenário cultural, e também como incentivadoras da produção artística nacional. Servem também para pensar particularidades e meandros de políticas de incentivo que ultrapassam questões orçamentárias e pragmáticas, além de ser mais um elemento de fortalecimento para a manutenção e estímulo a Programas de Graduação e Pós-graduação em Arte, nas Instituições de Ensino Superior (IES) tanto na esfera pública quanto na privada.

Voltando ao percurso da Filmes de Plástico, aos dois criadores juntaram-se André Novais de Oliveira, também criador e com raízes em Contagem, e Thiago Macêdo Correia, produtor. Como já anteriormente dito, não houve incentivos do Estado para todas as obras: esses recursos só vieram depois da execução de curtas veiculados e premiados em alguns festivais. Segundo a filmografia presente no website da produtora, o primeiro título que utilizou recursos públicos foi o curta-metragem Dona Sônia pediu uma arma para seu vizinho Alcides, de (2011) (cf. FILMES..., c2019). 
A estreia da produtora, em 2009, deu-se a partir de um curtametragem, Filme de sábado (2009), feito, conforme indicam os créditos iniciais, com recursos próprios e apoio institucional da Universidade em que os idealizadores (Gabriel e Maurílio Martins) estudavam. Um filme que, assim como outros de seus repertórios, convocava a máxima de Glauber Rocha, "Uma câmera na mão e uma ideia na cabeça". Nesse curta inaugural, o personagem principal se encontra aparentemente enfadado, em um dia nublado em sua casa, zapeando por canais de televisão. Seu tédio o impulsiona a construir para si um espaço de fruição ao qual não teria acesso imediato. Ele, de forma criativa, a partir de seus próprios recursos, simula, no quintal de sua casa, uma ambientação de praia, por meio da coleta de uma quantidade expressiva de areia que estava parada na calçada do vizinho. Tal ambientação é acrescida por objetos comuns às paisagens litorâneas, em especial, nos períodos de férias: cadeiras, guarda-sóis, baldes e pás de crianças. Os trajes escolhidos pelo personagem para passar aquela tarde no quintal de sua casa são também típicos: sandálias, óculos de sol, sunga e camisa florida.

O cenário vai ganhando, aos poucos, contornos cada vez mais pitorescos, à medida que o personagem adiciona elementos de seu imaginário ao ambiente que constrói. Um elemento muito singular em toda sequência é a presença de uma baleia inflável, o qual se tornou símbolo da produtora mineira e faz parte de sua logomarca. Em uma espécie de escala, o artificialismo do ambiente fica cada vez mais patente. Primeiramente com a chegada de um novo personagem, um vendedor de picolés de rua, o qual é chamado pelo protagonista para atuar junto a ele naquela paisagem simulada. Posteriormente há a reprodução do som do mar, a partir de um aparelho eletrônico e, por fim, há a inserção de um canhão de luz, chamado fresnel, tipicamente usado em produções cinematográficas, para simular o efeito luminoso da luz solar. Este último recurso é inserido no espaço após uma chuva que quase destruiu a paisagem construída e a fruição do protagonista.

Filme de sábado estabelece um contrato de reconhecimento com o espectador a que ele se destina em primeira instância, o mineiro. Contrato que se estabelece por meio de vários índices de identificação, como o sotaque dos personagens, e também por meio de uma realidade cara ao habitante desse estado, o fato de Minas Gerais não ser banhado pelo mar. Vários locais brasileiros também não se encontram no litoral, assim possivelmente tal realidade, muitas vezes seguida de frustração, 
pode ser compartilhada entre os sujeitos dessas outras regiões. Além dessa questão física, há também o aspecto simbólico que pode ser pensado como índice de reconhecimento do espectador. O litoral, a praia e o mar muitas vezes estão associados ao lazer e ao prazer que muitos brasileiros não podem usufruir não só pela distância geográfica como também por motivações econômicas, uma vez que as regiões litorâneas, por seu alto potencial turístico, muitas vezes possuem um custo de vida elevado, sobretudo em épocas de altas temporadas.

$\mathrm{O}$ ato de construir uma praia em seu quintal produz um jogo dúbio, pois, ao mesmo tempo que aproxima o público pela constatação da falta, pode também afastá-lo, ao desenhar uma caricatura irônica de um sujeito incapaz de fruir sua própria realidade, ao modificá-la de forma completamente artificial. Essa mesma caricatura pode indicar a potência do sujeito em criar alternativas mesmo que a realidade seja aparentemente adversa. Pautado nesse aspecto, o filme sugere também uma dimensão biográfica e metalinguística. Ao abordar uma situação em que o sujeito - ao não possuir acesso a locais onde almejaria estar, ou quem sabe não possuir condições para executar um determinado desejo -, acaba por inventar e criar, de forma alternativa, condições de possibilidade para efetivá-lo, tal qual fizeram os realizadores do filme ao produzir o curta a partir de suas próprias realidades e orçamentos.

Vários significados podem ser extraídos de Filme de sábado, bem como outros elementos de reflexão e de índices que promovam o reconhecimento do espectador, os quais necessitariam de um estudo mais ampliado a fim de projetar determinadas nuances. Mesmo assim, a necessidade de trazer quase toda a sequência desse primeiro curta da Filmes de Plástico se justifica, pois ela indica várias escolhas estéticas, algumas ainda rudimentares e ingênuas à época, perseguidas pelos cineastas em produções posteriores. Um aspecto que chama a atenção é o teor prosaico e descontraído da narrativa, com requintes de humor, inserido em uma atmosfera capaz de questionar o absurdo do cotidiano humano. Tal característica pode ser observada em outros filmes da produtora e é muito explorada por André Novais, por exemplo, no curta Quintal (2015). Nesse filme, há uma construção que joga com a percepção do espectador. Os primeiros quadros exploram a rotina monótona de um casal de idosos, porém, após um vendaval, essa rotina é abruptamente interrompida e o espectador é surpreendido com um desfecho extremamente diferente do que se figurava nas primeiras cenas. 
Tal qual o personagem, o público é absorvido por um portal que o retira da normalidade temporariamente estabelecida.

Mesmo com esses contornos descontraídos e fantasiosos, é notório que a dimensão do cotidiano e da vida comum dos personagens é um elemento crucial para a construção estética proposta pelos criadores. Ficção e realidade em muitas obras da produtora não possuem fronteiras e em alguns casos são levadas ao seu limite, como é o caso de Quintal e Ela volta na quinta (2014), ambos interpretados pelos pais de André Novais. O primeiro, como já dito, é marcado por elementos absurdos, já o segundo é um longa de características mais sóbrias. Em Ela volta na quinta, as personagens se confundem com os atores, vivenciando um roteiro pré-estabelecido alternado com elementos de suas próprias vidas. O longa estabelece, com isso, uma zona indeterminada entre o biográfico e ficcional.

Provocar o público por meio de zonas ambíguas e sensíveis entre realidade e ficção está nos alicerces estéticos dos cineastas da Filmes de Plástico. Apesar de eles não utilizarem os mesmos procedimentos para produzir essas tensões, há uma constante em seus trabalhos, a qual se deve ao conhecimento e manejo acurados que eles possuem do espaço onde são criadas suas histórias, bem como do sujeito que anda, transita e vive por esses locais. Desde Filme de sábado, a casa, a rua, o bairro, a vida e as pessoas que habitam a periferia de Contagem são imagens potentes e marcantes em suas produções. Gabriel, Maurílio, André e Thiago, ao longo de onze anos, reencenam, contemporaneamente, em solo brasileiro, um percurso que está presente em um aforismo de Walter Benjamin, composto entre os anos de 1925 e 1934. Para o filósofo alemão, a noção de subúrbio, já naquela época, relacionava-se diretamente a questões políticas.

Subúrbios. Quanto mais nos afastamos do centro, tanto mais politizada se torna a atmosfera. Aparecem as docas, os portos fluviais, os armazéns, os alojamentos da pobreza, os esparsos asilos da miséria: os arredores. Os arredores são o estado de sítio da cidade, o terreno no qual brame ininterruptamente a grande batalha decisiva entre a cidade e o campo. (BENJAMIN, 1987, p. 202.)

O "subúrbio", ou a periferia, é uma espécie de códice gravado nas câmeras e nos olhares dos realizadores, ou mesmo um órgão fundamental, 
pulsante e necessário para a elaboração de seus projetos cinematográficos, tal qual um coração que bombeia o sangue para que o corpo execute suas funções vitais. Sem a radicalização, em termos de enredo e argumento, explorada no longa de Novais de 2014, No coração do mundo (2019) manteve o DNA estético e político de seus produtores, ao entranhar pelas casas, vielas, becos, ruas e avenidas de Contagem, muitas vezes conduzindo o espectador por meio do ônibus 2130, ou por ousados motoqueiros que aceleram e empinam suas motos pelas avenidas dos bairros. $\mathrm{O}$ corpo e o sujeito dessa periferia estão intimamente ligados às imagens que o filme propõe, mesmo que haja atores que nunca viveram por aquelas paragens.

No coração do mundo possui direção e roteiros assinados por Gabriel Martins e Maurílio Martins, e traz um elenco composto por nomes como: Leo Pyrata, Kelly Crifer, Grace Passô, Bárbara Colen, Robert Frank, Rute Jeremias, Renato Novaes, Mc Carol de Niterói, Glaucia Vandeveld, Eid Ribeiro, Karine Teles, Rejane Faria, Russão, entre outros. Segundo a sinopse, seu enredo narra a história do personagem Marcos (Leo Pyrata), que busca sair de sua rotina de trabalhos esporádicos e pequenos delitos, a partir do plano de um assalto proposto por sua amiga Selma (Grace Passô). Para tanto, ele precisa convencer sua namorada, Ana (Kelly Crifer), a participar do ato. Paralelamente ao desenrolar dessa narrativa, correm outras histórias que compõem, mesmo que parcialmente, uma espécie de quadro demográfico do bairro onde é ambientado o filme.

Para quem acompanha a filmografia da produtora, fica claro que parte do argumento do filme foi extraído de curtas anteriores: Dona Sônia pediu uma arma para seu vizinho Alcides (2011) e Contagem (2010). Quase todos os atores e as atrizes que atuaram nessas outras montagens participam do elenco do longa. Em Contagem, há um enredo que acompanha cinco personagens: Marcos, Ana, Rose (Bárbara Colen), Miro (Robert Frank) e o pai de Ana, os quais interagiam em espaços bem específicos: no interior de um carro, em uma pequena loja, em uma praça, em uma laje ou no interior da casa de Ana. Há três narrativas em paralelo no curta, as quais, ainda que delimitadas pelo ponto de vista de suas personagens, entrecruzam-se constantemente. A principal prioriza o ponto de vista de Ana, a partir de suas ações de entregar as chaves de sua casa a Marcos; caminhar pela rua até uma praça, onde é interrompida por Rose em um diálogo vazio e trivial; entrar em uma loja para comprar 
um picolé e, ao abri-lo, deixa-o cair. Logo em seguida, ouve-se um tiro. A segunda elege o ponto de vista de Rose. Esta segunda narrativa se inicia a partir de um diálogo, dentro de uma loja, entre Miro e Rose; posteriormente, Rose caminha até a praça onde se encontra com Ana e reproduzem o rápido diálogo anteriormente citado e se despedem. A terceira narrativa, por sua vez, focaliza o ponto de vista de Marcos, a partir da sequência em que ele recebe as chaves, entra na casa de Ana e atira no pai dela (o mesmo tiro ouvido por Ana no momento em que cai seu picolé). Ao sair da casa de sua namorada, ele avista um avião no céu e aponta a arma como se fosse atirar.

Em meio a essas três sequências, há cenas que funcionam como uma espécie de fluxo de consciência de Ana ou de Marcos. Em alguns momentos do curta há cortes que realizam flashbacks, um deles é o café da manhã entre ela e o pai. Além dessa cena, há outra que interrompe o fluxo narrativo do curta, a qual não é possível determinar se remete ao passado ou ao futuro das três sequências guias do enredo. Em uma laje, Ana e Marcos conversam e falam de seus sonhos. Na conversa íntima, na laje, surge pela primeira vez a expressão: "No coração do mundo", a partir de um improviso de Leo Pyrata, segundo os diretores.

Apesar de o longa possuir uma fruição narrativa independente dos curtas que lhe deram origem, o enredo presente retratado no filme de 2019 é anterior ao da produção de 2010. No coração do mundo abre suas lentes, dilata o tempo daqueles personagens. Eles percorrem outros lugares e paisagens do bairro Laguna. Os microrretratos daquela localidade compostos pelos outros filmes se expandem. Ao se expandirem, outras histórias percorrem o interior daquelas paisagens suburbanas e periféricas. Outras narrativas ficam expostas, e as conhecidas figuras dos anteriores curtas se adensam, sem, contudo, completarem-se. Na produção de 2019, os personagens são mais desenvolvidos e revelam camadas mais sensíveis que nos curtas anteriores. A lacunar e misteriosa personagem de Dona Sônia (Rute Jeremias), por exemplo, no curta de 2011 já se revelava como uma senhora solitária e amargurada pela perda violenta de Joca. Porém os meandros de seu ato de matar aquele que assassinou seu filho são aprofundados no filme de 2019, justamente pela construção do algoz de sua cria, Beto (Renato Novaes). No longa, esse personagem vive em meio à violência, devido ao seu envolvimento com o tráfico de drogas, porém ele é acolhido, muitas vezes a contragosto, pelo seu irmão Miro, o qual possui uma relação de adultério com Rose 
(esses últimos personagens estão presentes no curta Contagem). É a partir desse núcleo de personagens que os enredos dos curtas de 2010 e 2011 se cruzam, tornando-se materiais de composição para a produção de 2019. Assim, mesmo que a personagem de Dona Sônia não possua um diferencial evidente em seus aspectos, já delineados no curta de 2011, o contexto em que é desenvolvida sua narrativa está repleto de detalhes que enriquecem a percepção do público para os vários personagens que compõem o filme No coração do mundo.

A montagem desse longa é marcada pelo destino das já citadas personagens Marcos e Ana, porém as noções de protagonistas são borradas pelos modos como as histórias são arquitetadas. A própria personagem Selma, que não existia nos curtas anteriores, carrega um lugar de destaque, visto que é a partir dela que há um dos principais fios condutores do enredo. No entanto, como já apontado por diversas críticas e percebido pelos espectadores, não é possível resumir a trama apenas ao assalto arquitetado por Selma e Marcos. Tampouco seria desajustado dizer que a função de protagonista é dada ao bairro onde transcorre a maioria dos conflitos do filme.

Antes dos fatos que a ficção enuncia, há o espaço, as histórias e as memórias subjacentes que compõem uma espécie de mapa sócio-histórico da região em que o filme é rodado. Tais conteúdos submergem no filme devido à presença literal dos habitantes das locações na montagem, e, principalmente, ao imaginário que moradores, alguns atores e diretores comungam em relação àquele lugar. A construção da obra não se baseia em uma visão romantizada do local, muito menos possui um ponto de vista que busca somente denunciar seus problemas. A violência, a desigualdade, a rotina, os desejos, as memórias daquele espaço estão reunidas no filme. Para o espectador que assistiu ao curta Contagem, o bairro e a região são tomados, no longa, como temas mais profundos, pois, ainda que algumas locações se repitam, o ator e o espectador são levados a conhecer mais profundamente os locais, suas belezas, seus horrores e suas contradições. Por meio de um recurso de zoom, os espectadores adentram as casas e as intimidades daqueles personagens e passam a perceber a periferia em suas frestas, em suas ruas, praças, casas, em seus automóveis, motocicletas e transportes coletivos, em seus salões, em seus armazéns e bares. No entanto, ainda que haja uma ampliação do ponto de vista do espectador a respeito das pessoas e da região, tal qual o efeito produzido por uma lente grande angular, há ainda espaços 
para distorções e uma inerente incompletude. A cidade de Contagem, no longa-metragem, não se revela por inteiro, mas se mostra com maior amplitude. Não há espaços, nas obras da Filme de Plástico, para lidar com a possibilidade de resolução e completude.

Acessar o filme a partir de um olhar que busca captar a narrativa do espaço (e também como uma grande homenagem de seus realizadores ao lugar que foi cúmplice de seu crescimento, trabalhos, bem como foi um colaborador de seus imaginários) confere outra fruição a algumas passagens presentes na montagem. Dentre as várias cenas em que se pode assumir essa determinada leitura, há três momentos, em especial, que atribuem um olhar de gratidão e de respeito ao bairro, mas também de atenção, de ressalva, de crítica e de cuidado. O primeiro deles é a abertura do filme. Em meio à música de Lara Fabian, Love by grace, mostra-se o bairro em plano aberto à noite. Ao fundo, no canto superior direito, aparecem fogos de artifícios. Depois do corte da câmera, é revelado para o público que tanto a música quanto os fogos provêm de um carro de mensagens parado na praça principal. Neste momento, ocorre a primeira fala do filme, que sugere uma grande saudação ao bairro: "Boa noite, Laguna! [...] Alguém aqui é muito amado e muito especial e vai receber aqui uma homenagem muito especial". Os próprios diretores dizem que essa mensagem, colocada nos primeiros momentos, foi justamente para saudar os possíveis espectadores do bairro que porventura estivessem em alguma sala de cinema onde o filme pudesse estar sendo exibido ('NO CORAÇÃO..., 2019).

Os créditos iniciais do filme são também exaltados pelos diretores, embalados pela letra e música de MC Papo, Texas. Neles há uma sequência de imagens de moradores do bairro, bem como de suas paisagens. Tais créditos revelam a cultura periférica, embalada pelo ritmo do rap e de passos de dança conduzidos por um grupo de jovens da região. A trilha escolhida se associa diretamente com essa abordagem do espaço, sem romantizá-lo (cf. MC PAPO, c2018). A letra de MC Papo relaciona tanto Belo Horizonte quanto as cidades de Ribeirão das Neves, de Santa Luzia, de Betim e de Contagem ao estado norteamericano Texas. Essa associação está carregada de um imaginário que vê tanto o espaço estrangeiro de um país superindustrializado quanto a região metropolitana de Belo Horizonte como locais onde se misturam um mundo rural e um mundo urbanizado. 
O estado norte-americano, Texas, possui uma iconografia muito marcada no imaginário cinematográfico, o qual remete às produções de filmes de bangue-bangue. Nessas narrativas, há uma ambientação que privilegia muitos elementos do espaço rural, como fazendas, criações, além da paisagem. Há também, conforme indica o nome — uma onomatopeia do gênero - várias sequências de tiros e violência. Muitas vezes parece que as leis não cumprem funções reguladoras e quase todos os assuntos se resolvem pela força, violência e confrontos. A partir dessas imagens relacionadas à região texana, motivada por essa filmografia, o compositor e interprete $\mathrm{MC}$ Papo associa as cidades próximas à capital - bem como a própria Belo Horizonte - ao Texas, ou seja, a um local repleto de contradições e violência, disputas de poder, consumo e venda de drogas. Na música o conjunto das cidades mineiras citadas é nomeado como "roça grande", onde há uma grande confluência cultural desde roupas de grandes grifes bem como aspectos identitários como um sotaque característico, entre outros.

A terceira passagem reveladora desse local, por sua vez, é uma das mais paradigmáticas cenas do filme. É o momento em que Selma, ao preparar uma sessão de fotos que faria com alunos de uma escola pública, senta-se na cadeira e pede para Marcos conferir o enquadramento. Uma vez enquadrada no cenário em que há um mapa-múndi ao fundo, livros e cadernos simetricamente dispostos em uma mesa, a personagem enuncia o seguinte texto: "Coração do mundo... é o próximo lugar, pra onde a gente quer ir... melhor, muito melhor. Aonde a gente quer pisar... pra onde vai o desejo da gente. Aqui não é mais meu coração do mundo, não. Já foi, não é mais, acabou." "A Ao pronunciar essas palavras, a personagem revela que há um lugar, o qual ela não sabe ao certo, onde será possível encontrar os seus desejos. Uma espécie de Pasárgada, valendo-se de um cenário poético composto por Manuel Bandeira (1974). Para uns, esse lugar já não é mais seu local de origem; para outros, que perderam suas referências, o local onde nasceram e cresceram pode ser considerado como esse espaço idílico do desejo, enunciado pela personagem. Segundo os diretores, suas produções permitem um reencontro com esse local, o qual outrora não era "o coração do mundo", "mas agora é" (NO CORAÇÃO..., 2019).

\footnotetext{
${ }^{4}$ Transcrição da fala da personagem Selma (Grace Passô). Um link de acesso para o filme, em plataforma Vimeo, foi gentilmente cedido pelos realizadores, a fim de que o presente artigo fosse desenvolvido.
} 
Esses três momentos são apenas recortes para se pensar o modo como o bairro, suas memórias e seus moradores, além de substratos e matérias de composição, são também elementos narrativos que ocupam lugares de relevância na obra. No coração do mundo não pretende ser um retrato global e coletivo de identidades e realidades brasileiras, tampouco mineiras, ainda que o sotaque das Minas Gerais prevaleça na boca da maioria dos atores. Um ponto de inflexão sobre essa identidade sonora encontra-se na personagem interpretada por MC Carol de Niterói, atriz e funkeira, marcada pela prosódia e léxico comuns em comunidades periféricas da cidade do Rio de Janeiro.

Uma das pretensões desse longa e, por extensão, da maioria dos outros curtas-metragens que o precederam, produzidos pela Filmes de Plástico, é um recorte e um olhar sensível para bairros de uma cidade mineira chamada Contagem, localizada na Região Metropolitana de Belo Horizonte. Antes de fazer um retrato do local, eles querem localizar, para seu espectador, onde o bairro se situa e, principalmente, trazer para a tela, a partir de seus próprios olhares, o sujeito que vive no bairro Laguna. Um sujeito periférico, que não quer ser visto a partir de um olhar universalista, o qual possa inseri-lo em um estereótipo ou mesmo em uma única e imutável identidade. Desse modo, os sujeitos periféricos que são representados nos filmes, bem como aqueles que produzem essas representações, estão dispostos a exportar suas ideias, desejos, vontades, realidades e percepções. Pessoas que se incluem na perspectiva de mercado que, desde a virada do século XX para o XXI, lhes exigiu uma postura cosmopolita, como havia apregoado Silviano Santiago (2004). Tal inserção se dá a partir de seus próprios recursos e criatividade, fortalecidos muitas vezes pelas perspectivas abertas de leis de fomento à cultura e de outros programas sociais,

Nesse último longa da produtora mineira, a cidade de Contagem se abre para o mundo. Ela se mostra com vários significados e identidades. Os produtores, ao realizar esse trajeto de dez anos de produção de filmes, não se propõem a uma viagem de reconhecimento pessoal de quem perdeu suas origens, como o ator francês de Viagem ao começo do mundo (1997), de Manoel de Oliveira. Tampouco buscam trilhar uma viagem à memória do local entoando mitos de um possível passado heroico, tal qual se propunha a personagem do diretor dessa mesma produção luso-francesa, criticada por Silviano Santiago em seu texto de 2004. As memórias das pessoas e do espaço, nessa produção cinematográfica mineira, estão 
recortadas no presente, a partir da inscrição dessas reminiscências que sobrevivem nos corpos dos sujeitos que estão presentes nos filmes. Uma memória potente, uma força capaz de resistência e de luta contra projetos homogeneizadores, e por vezes eugenistas, que muitas vezes negam e negligenciam o que é feito por corpos negros, pobres, homossexuais, transexuais e por outras minorias. No coração do mundo não é uma mera viagem de retorno às origens e às raízes dos produtores, é a possibilidade de se mostrar como parte integrante de um mundo globalizado, multicultural e cosmopolita.

Por meio dessas propostas, a produtora executa um duplo movimento, pois, ela quer dar a ver a vida, as pessoas e as identidades diversas que compõem a comunidade onde os diretores foram criados, e ao mesmo tempo quer que o próprio sujeito se veja e, possivelmente se reconheça nessas obras. Os realizadores da Filmes de Plástico reconhecem, conforme dito por Didi-Huberman (2011, p. 153), "a essencial vitalidade das sobrevivências e da memória em geral [ao encontrar] as formas justas de sua transmissão". Eles propõem um movimento de espelho, mas um espelho capaz, não somente de refletir uma imagem, mas um espelho rachado, que indica fissuras do sujeito representado, que duplica uma imagem justamente para que ela não seja única e unívoca. Um espelho que aponta para várias direções, capaz de refletir vibrantes e sensíveis imagens de um local para ser visto, visitado e habitado.

\section{Referências}

ANCINE. Apresentação. In: PORTAL da Agência Nacional de Cinema. Rio de Janeiro: ANCINE, [200-?]. Disponível em: https://www.ancine. gov.br/pt-br/ancine/apresentacao. Acesso em: 13 jan 2020.

ANCINE. Uma nova política para o audiovisual: Agência Nacional de Cinema, os primeiros 15 anos. Rio de Janeiro: Ministério da Cultura, 2017. Disponível em: https://www.ancine.gov.br/sites/default/files/livros/ ANCINE\%2015\%20ANOS\%20WEB\%20FINAL_em\%20baixa2.pdf. Acesso em: 15 jan. 2020.

BANDEIRA, Manuel. Vou-me embora pra Pasárgada. In: . (org.). Poesia completa e prosa. Rio de Janeiro: Companhia José de Aguilar Editora, 1974. p. 222. 
BENJAMIN, Walter. Imagens do pensamento. In: . Rua de mão única. Tradução de Rubens Rodrigues Torres Filho, José Carlos Martins Barbosa. São Paulo: Brasiliense, 1987. p. 143-177. (Obras escolhidas, v. 2).

CONTAGEM. Direção: Gabriel Martins, Maurílio Martins. Contagem: Filmes de Plástico, 2010. Disponível em: https://www.filmesdeplastico. com.br/.

DIDI-HUBERMAN, Georges. Sobrevivência dos vaga-lumes. Tradução de Márcia Arbex, Vera Casa Nova. Belo Horizonte: Editora UFMG, 2011.

DONA Sônia pediu uma arma para seu vizinho Alcides. Direção: Gabriel Martins. Contagem: Filmes de Plástico, 2011. Disponível em: https:// www.filmesdeplastico.com.br/.

ELA volta na quinta. Direção: André Novais Oliveira. Contagem: Filmes de Plástico, 2014. Disponível em: https://www.filmesdeplastico.com.br/.

FILME de sábado. Direção: Gabriel Martins. Contagem: Filmes de Plástico, 2009. Disponível em: https://www.filmesdeplastico.com.br/.

FILMES de Plástico. [Contagem]: Filmes de Plásticos, c2019. Página oficial da produtora. Disponível em: https://www.filmesdeplastico.com. br/. Acesso em: 13 dez. 2019.

HALL, Stuart. A identidade cultural na pós-modernidade. Tradução de Tomaz Tadeu da Silva, Guacira Lopes Louro. 11. ed. Rio de Janeiro: DP\&A, 2011.

MAZUI, Guilherme. "Se não puder ter filtro, nós extinguiremos a Ancine”, diz Bolsonaro. G1 Globo, Brasília, 19 jul. 2019. Política. Disponível em https://g1.globo.com/politica/noticia/2019/07/19/se-naopuder-ter-filtro-nos-extinguiremos-a-ancine-diz-bolsonaro.ghtml. Acesso em: 13 jan. 2020.

NO CORAÇÃO do mundo. Direção: Gabriel Martins, Maurílio Martins. Contagem: Filmes de Plástico, 2019. Disponível em: https://www. filmesdeplastico.com.br/.

"NO CORAÇÃO do Mundo", novo filme da produtora "Filmes de Plástico" será lançado nesta quinta. Belo Horizonte: [s.n.], 2019. 1 vídeo (51 min.). Publicado pelo portalcanal O Tempo. Disponível em: https:// www.youtube.com/watch?v=OxvnPiMT2rY. Acesso em: 13 dez. 2019. 
MC Papo. Texas. In: VAGALUME: música é tudo, [S.l.: s.d.]: Vagalume Mídia, c2018. Disponível em: https:/www.vagalume.com.br/mc-papo/ texas.html. Acesso em: 20 jan. 2020.

PRODUTORA mineira "Filmes de Plástico" é homenageada na $13^{a}$ CineBH. In: PORTAL do $13^{\text {a }}$ CineBH International Film Festival. Belo Horizonte: Universo Produção, 2019. Disponível em: http://cinebh.com. br/noticia/produtora-mineira-filmes-de-plastico-e-homenageada-na-13cinebh. Acesso em: 13 jan. 2020.

QUINTAL. Direção: André Novais Oliveira. Contagem: Filmes de Plástico, 2015. Disponível em: https://www.filmesdeplastico.com.br/.

SANTIAGO, Silviano. O cosmopolitismo do pobre. In:

Cosmopolitismo do pobre: crítica literária e crítica cultural. Belo Horizonte: Editora UFMG, 2004. p. 45-63.

SCHWARZ, Roberto. Ideias fora do lugar. In: . Ao vencedor as batatas: forma literária e processo social nos inícios do romance brasileiro. São Paulo: Duas Cidades; Ed. 34, 2000. p. 9.

Recebido em: 3 de fevereiro de 22020. Aprovado em: $1^{\circ}$ de julho de 2020. 